\title{
One-pot hydrothermal synthesis and characterization of FeS2 (pyrite)/graphene nanocomposite.
}

\begin{abstract}
This work reports on the investigation of temperature, reaction time, $\mathrm{pH}$, concentration of graphene oxide (GO) and the effect of gelatin on the synthesis of pyrite structured $\mathrm{FeS} 2$ nanoparticles assembled on graphene nanosheets using a facile 'one-pot' hydrothermal method. The results of X-ray diffraction, Fourier transform infrared spectroscopy, Raman spectroscopy and electron microscopy confirmed the simultaneous formation of pyrite structured FeS2 and the reduction of GO, yielding a nanocomposite of the materials, through the hydrothermal process. The systematic investigation shows that the nanocomposite, comprising a uniform distribution of nanoparticles on the surface of the graphene sheets, is easily synthesized, providing that certain reaction criteria are achieved. The condition warrants that the reaction is carried out in the presence of gelatin with a concentration of 1.5 wt. $\% / \mathrm{v}$ in a $\mathrm{pH}$ of 11 at $200{ }^{\circ} \mathrm{C}$ for $24 \mathrm{~h}$. Photocurrent response of the samples showed that the nanocomposite with the $\mathrm{GO}$ concentration of $1 \mathrm{mg} / \mathrm{mL}$ produced the highest photocurrent value of about $1.01 \mu \mathrm{A}$, which is about 2.6 times higher than that obtained by the pure FeS2.
\end{abstract}

Keyword: Gelatin; Graphene; Hydrothermal; Nanocomposite; Pyrite. 